\title{
Therapeutic Effects of Vitamin D Analogs on Cardiac Hypertrophy in Spontaneously Hypertensive Rats
}

\author{
Juan Kong, ${ }^{{ }^{\dagger}}$ Gene H. Kim, ${ }^{\dagger}$ Minjie Wei, ${ }^{*}$ \\ Tao Sun, ${ }^{\dagger}$ George Li, ${ }^{\dagger}$ Shu Q. Liu, ${ }^{\ddagger}$ Xinmin Li, ${ }^{\S}$ \\ Ishir Bhan, ${ }^{\text {"I }}$ Qun Zhao, * Ravi Thadhani, ${ }^{\text {"ा }}$ \\ and Yan Chun $\mathrm{Li}^{* \dagger}$

\begin{abstract}
From the Laboratory of Metabolic Disease Research and Drug Development," Shengjing Hospital, China Medical University, Shenyang, China; the Department of Medicine, the Division of Biological Sciences, University of Chicago, Chicago, Illinois; the Evanston, Illinois; the Department of Pathology, ${ }^{\S}$ University of California, Los Angeles, California; and the Division of Nephrology Massachusetts General Hospital, ${ }^{\text {"ा }}$ Harvard Medical School, Boston, Massachusetts
\end{abstract} \\ Department of Biomedical Engineering, ${ }^{\ddagger}$ Northwestern University,
}

Vitamin D inhibits renin expression and blocks the compensatory induction of renin associated with the use of renin-angiotensin system inhibitors. Here we test the therapeutic effects of two commonly used vitamin $D$ analogs and their combination with losartan on the development of left ventricular hypertrophy. One-month-old male spontaneously hypertensive rats were treated with vehicle, losartan, paricalcitol, doxercalciferol, a combination of losartan and paricalcitol, or a combination of losartan and doxercalciferol for 2 months. Blood pressure was markedly reduced by losartan, but not by paricalcitol or doxercalciferol alone. Echocardiograpy demonstrated a 65 to $80 \%$ reduction in left ventricular wall thickness with losartan, paricalcitol, or doxercalciferol monotherapy and almost complete prevention of left ventricular hypertrophy with the combination therapies. Attenuation of cardiac and cardiomyocyte hypertrophy, and suppression of atrial and brain natriuretic peptides, were most marked in the combination therapy groups. These changes were well correlated with left ventricular gene and microRNA expression profiles in the different treatment groups. Renal and cardiac renin expression was markedly increased in losartan-treated animals, but nearly normalized with combination therapy. The same vitamin $D$ analogs suppressed plasma renin activity in patients receiving chronic hemodialysis. These data demonstrate that vitamin $D$ analogs have potent anti- hypertrophic activity in part via suppression of renin in the kidney and heart, and combination of these analogs with losartan achieves much better therapeutic effects because of the blockade of the compensatory renin increase. (Am J Pathol 2010, 177:622-631; DOI: 10.2353/ajpath.2010.091292)

In the general US population, serum 25-hydroxyvitamin D levels are inversely associated with several cardiovascular risk factors, including hypertension, diabetes, obesity, and hyperlipidemia. ${ }^{1}$ Low levels of serum 25-hydroxyvitamin $\mathrm{D}$ and 1,25-dihydroxyvitamin $\mathrm{D}\left[1,25(\mathrm{OH})_{2} \mathrm{D}_{3}\right]$ are associated with congestive heart failure and an increased rate of all-cause and cardiovascular mortality. ${ }^{2-4}$ Prospective studies have demonstrated an association between low serum 25-hydroxyvitamin D levels and increased risk of incident cardiovascular disease and myocardial infarction. ${ }^{5,6}$ In patients with chronic kidney disease, where cardiovascular disease is the leading cause of death, therapy with activated vitamin $D$ is associated with a reduction in mortality. ${ }^{7,8}$

Vitamin D's cardiovascular effects may be mediated in part by regulation of the renin-angiotensin system (RAS). ${ }^{9,10} 1,25(\mathrm{OH})_{2} \mathrm{D}_{3}$ and its analogs inhibit renin expression in vivo ${ }^{11}$ and an inverse correlation has been reported between levels of serum $1,25(\mathrm{OH})_{2} \mathrm{D}_{3}$ and plasma renin activity in humans. ${ }^{12,13} \mathrm{~A}$ therapeutic effect of vitamin D in humans, however, has not been conclusively demonstrated. Pharmacological inhibition of the RAS with angiotensin converting enzyme (ACE) inhibitors or angiotensin II receptor blockers (ARBs) is commonly

Supported by research grants from Genzyme Corp., Abbott Laboratories, National Natural Science Foundation of China (grant 30971401), and National Institutes of Health-National Heart, Lung, and Blood Institute (grants HL085793 and HL093954).

R.T. and Y.C.L. are cosenior authors.

Accepted for publication April 19, 2010.

Address reprint requests to Yan Chun Li, Ph.D., Shengjing Hospital, China Medical University, Shenyang, China, and Department of Medicine, University of Chicago, 900 E. 57th Street, KCBD, Mailbox 9, Chicago, IL 60637; or Ravi Thadhani, M.D., M.P.H., Renal Unit, Massachusetts General Hospital, Harvard Medical School, Boston, MA 02114. E-mail: cyan@medicine. bsd.uchicago.edu or thadhani.ravi@mgh.harvard.edu. 
used in the management of cardiovascular disease. However, the therapeutic efficacy of current RAS inhibitors may be compromised by a compensatory increase in renin production caused by interruption of a negative feedback loop, ${ }^{14,15}$ potentially leading to suboptimal clinical outcomes. Recently, we demonstrated that the compensatory renin induction could be blocked by vitamin $\mathrm{D}$ analogs in combination with AT1 receptor antagonists, and the combination strategy generated therapeutic synergism in the prevention of diabetic kidney disease progression in animal models. ${ }^{16,17}$

Left ventricular hypertrophy (LVH) is a major risk factor for coronary ischemia, congestive heart failure, and cardiac arrhythmias, and may link vitamin $D$ deficiency with cardiovascular mortality. Genetic studies using mutant mice lacking the vitamin $D$ receptor or Cyp27B1, the cytochrome P450 enzyme catalyzing $1,25(\mathrm{OH})_{2} \mathrm{D}_{3}$ biosynthesis, have established a correlation between vitamin $D$ receptor- or $1,25(\mathrm{OH})_{2} \mathrm{D}_{3}$ deficiency and cardiac hypertrophy, which involves the activation of the systemic and cardiac RAS. ${ }^{9,18,19}$ Treatment with activated vitamin $\mathrm{D}$ attenuated the development of LVH in Dahl salt-sensitive rats ${ }^{20}$ and rescued the cardiac phenotype of the Cyp27B1-null mice. ${ }^{19}$ In this study, we examined the therapeutic effect of two commonly used vitamin D analogs (paricalcitol and doxercalciferol) and an AT1 receptor antagonist (losartan) on LVH in spontaneously hypertensive rats (SHRs), an established model for human essential hypertension and LVH, with mono- and combination therapy.

\section{Materials and Methods}

\section{Animals and Treatment}

One-month-old male SHRs and nonhypertensive WKY rats purchased from Charles River Laboratories (Wilmington, MA) were randomized into six groups $(n=4)$ and treated, respectively, with vehicle ( $\mathrm{V}$, propylene glycol: $\mathrm{H}_{2} \mathrm{O}=80: 20$, i.p. injection, three times per week), losartan (L, at $30 \mathrm{mg} / \mathrm{kg} /$ day, dissolved in drinking water), paricalcitol ( $P$, 19-nor-1,25-dihydroxyvitamin $D_{2}$ at 400 ng/kg; provided by Abbott Laboratories), and doxercalciferol (D, $1 \alpha$-hydroxyvitamin $\mathrm{D}_{2}$ at $400 \mathrm{ng} / \mathrm{kg}$, provided by Genzyme; both analogs dissolved in the vehicle, i.p. injection, three times per week), losartan + paricalcitol $(L+P)$ or losartan + doxercalciferol $(L+D)$ for 2 months. The doses of the two vitamin $D$ analogs have been used previously in animals with minimal calcemic effect. ${ }^{16,17,20}$ No mortality or heart failure was seen during the study in any of these rats, with or without treatment. WKY rats served as nonhypertensive controls (C). At the end of the treatment, blood pressure of these rats was determined using the carotid artery cannulation method as reported previously. ${ }^{9}$ Animals were sacrificed immediately by exsanguination. The serum and plasma were collected and stored at $-80^{\circ} \mathrm{C}$. The heart and kidneys were harvested immediately, weighed, and used for RNA and protein preparation or processed for histology analyses. The animal study protocol was approved by the Institutional
Animal Care and Use Committee at the University of Chicago.

\section{Echocardiography}

Transthoracic echocardiography was used to examine the cardiac parameters of the rats at the end of the treatment, using a 15.0-MHz imaging transducer with a Phillips 7500 ultrasound machine. Echocardiography was performed under inhaled isoflurane $(\sim 1 \%)$ for anesthesia, delivered via nosecone. Chest hairs were removed with a topical depilatory agent. Limb leads were attached for electrocardiogram gating, and the animals were imaged in the left lateral decubitus position. Body temperature was maintained using a heated platform and warming lamps. Two-dimensional cardiac imaging was performed in the parasternal long-axis and short-axis views at the midventricular level. M-mode images were obtained for measurements of wall thickness and chamber dimensions.

\section{Histology and Immunostaining}

Freshly dissected heart and kidneys were fixed overnight with 4\% formaldehyde made in PBS ( $\mathrm{pH} 7.2$ ), processed, embedded in paraffin, and cut into $3-\mu \mathrm{m}$ sections for H\&E staining. Cardiomyocytes were stained with FITClabeled wheat germ agglutinin (Sigma-Aldrich, St. Louis, $\mathrm{MO}$ ) and viewed using a fluorescence microscope. The diameter of cardiomyocytes was measured using computer software ImageJ (National Institutes of Health, Bethesda, MD), and 50 cells/mouse were randomly selected for quantitation. Paraffin sections were first boiled in $10 \mathrm{mmol} / \mathrm{L}$ sodium citrate solution $(\mathrm{pH} \mathrm{6.0)}$ for 10 minutes to retrieve the antigens before antibody staining. The sections were stained with primary antibodies, followed by incubation with horseradish peroxidase-conjugated secondary antibodies. Antigens were visualized with a peroxidase substrate diaminobenzidine kit (Vector Laboratories, Burlingame, CA).

\section{Western Blot}

Kidneys were homogenized in Laemmli buffer (Boston Bioproducts, Worcester, MA), followed by 5 minutes boiling and centrifugation to obtain the supernatant. Protein concentrations were determined using a Bio-Rad Protein Assay kit (Bio-Rad, Hercules, CA). SDS-polyacrylamide gel electrophoresis and Western blotting were performed as described previously. ${ }^{21}$ The intensity of the protein bands was quantified using gel analysis software UNSCAN-IT gel version 5.3 (Silk Scientific, Orem, UT) and presented as fold changes.

\section{Northern Blot}

Total RNAs were extracted from the left ventricles using TRIzol reagents (Invitrogen, Carlsbad, CA). Northern blot analysis was performed as described previously. ${ }^{21}$ 
Briefly, total RNAs were separated on $1 \%$ agarose gels containing $0.6 \mathrm{M}$ formaldehyde and transferred to nylon membranes followed by UV cross-linking. Hybridization was performed at $63^{\circ} \mathrm{C}$ in the hybridization buffer described by Church and Gilbert ${ }^{22}$ with a cDNA probe labeled with ${ }^{32}$ P-dATP using the Prime-a-Gene Labeling System (Promega, Madison, WI). Membranes were exposed to X-ray films at $-80^{\circ} \mathrm{C}$ for autoradiography, and mRNA signals were quantified using a Phosphorlmager.

\section{cDNA Microarray}

cDNA microarrays were performed using an Affymetrix GeneChip Rat Genome 2302.0 Array that contains over 30,000 transcripts. Target preparation followed the protocol provided by Affymetrix, using $5 \mu \mathrm{g}$ of total RNAs. cDNA and cRNA synthesis, cRNA chip hybridization and data scanning were performed according to the standard procedures. The acquisition and initial quantification of array images were achieved using the Affymetrix GeneChip Command Console software. Data analyses were performed using the D-Chip with CEL files. Thresholds for selecting differentially expressed genes were set at a relative difference $>1.5$-fold (or twofold), absolute difference $>100$ signal intensity units and statistical difference at $P<$ 0.05 . Genes had to meet all three criteria simultaneously to be considered as a significant change. Box-plot, cluster analysis and PCA analysis were conducted using Partek Genomic Suite 6.4.

\section{MicroRNA Microarray}

MicroRNA (miRNA) arrays were performed using an Exiqon miRCURY LNA miRNA Array, which includes 927/ 648/351 human/mouse/rat miRNAs as well as 438 miRPlus miRNAs. One microgram of total RNAs was used for labeling. The labeled miRNAs were hybridized to the Exiqon miRNA array $\mathrm{V} 11$ according to manufacturer's instructions. The miRNA array slides were scanned using Axon GenePix 4100A scanner and processed with the GenePix Pro 6.0 software. The raw miRNA data were normalized using a combination of house keeping miRNAs and invariant miRNAs. Statistically different miRNAs were selected using Partek genomic suite 6.4 with thresholds of fold change $\geq 1.5$ and $P<0.05$.

\section{$R T-P C R$}

First-strand cDNAs were synthesized from $2 \mu \mathrm{g}$ of total RNAs in a $20 \mu$ reaction using Moloney murine leukemia virus reverse transcriptase (Invitrogen) and hexanucleotide random primers. The first strand cDNA served as the template for PCR performed using a BioRad DNA Engine or an Applied Biosystems 7900 Real Time PCR System with a SYBR green PCR reagent kit (Applied Biosystems, Foster City, CA) as described previously. ${ }^{23}$ The PCR primers for renin were described previously. ${ }^{24}$ Levels of miR-208 in the left ventricle were quantified by real time RT-PCR using a commercial TaqMan miRNA

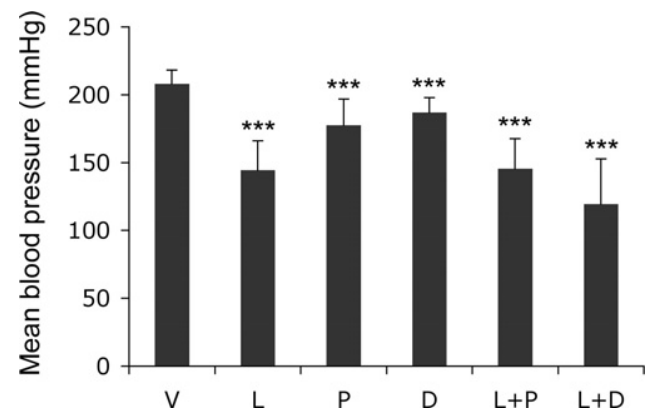

Figure 1. Effect of drug treatments on blood pressure. One-month old male SHRs were treated with vehicle $(\mathrm{V}), \operatorname{losartan}(\mathrm{L}, 30 \mathrm{mg} / \mathrm{kg})$, paricalcitol (P $400 \mathrm{ng} / \mathrm{kg}$ ), doxercalciferol (D, $400 \mathrm{ng} / \mathrm{kg}), \mathrm{L}+\mathrm{P}$ or L+D for two months. Mean blood pressure was determined at the end of treatment. ${ }^{* * * *} P<0.001$ vs vehicle; $n=4$.

assay kit with miR-208-specific TaqMan probe (Applied Biosystems).

\section{Human Studies}

Chronic hemodialysis patients $(n=28)$ with plasma samples available at two time points, within 14 days of dialysis initiation (baseline) and at $\sim 90$ days thereafter, were tested for plasma renin activity. Eleven subjects received no vitamin $D$ analogs between days 14 and 90 , whereas 17 subjects received at least 30 days of therapy (either paricalcitol or doxercalciferol, i.v. delivery) in this same period of time. Samples were drawn while the patient was sitting, before initiation of the routine dialysis session at both time points. Plasma samples were transported at room temperature. Plasma renin activity was measured by radioimmunoassay for the conversion of angiotensin I and expressed as ng Angiotensin I/ml/hr (Quest Diagnostics). No patients were receiving renin-inhibition therapy, and no subjects were receiving other therapies to reduce blood levels of parathyroid hormone. This clinical study was approved by Institutional Review Board at Massachusetts General Hospital.

\section{Statistical Analysis}

Data values were presented as means \pm SEM. Statistical comparisons were made using Student's $t$-test, analysis of variance, and $\chi^{2}$ tests, and log transformed, as appropriate, with $P<0.05$ being considered statistically significant. All $P$ values obtained in the analyses are twosided $P$ values.

\section{Results}

We first assessed the effect of the different treatments on serum calcium and blood pressure in SHRs. At the end of the study period, serum calcium levels were slightly increased (by 10 to $23 \%$ relative to the vehicle-treated group) in all groups receiving vitamin D analogs, but only the changes in the combination treatment groups reached significance $(P<0.05)$. As expected, v-treated 
A

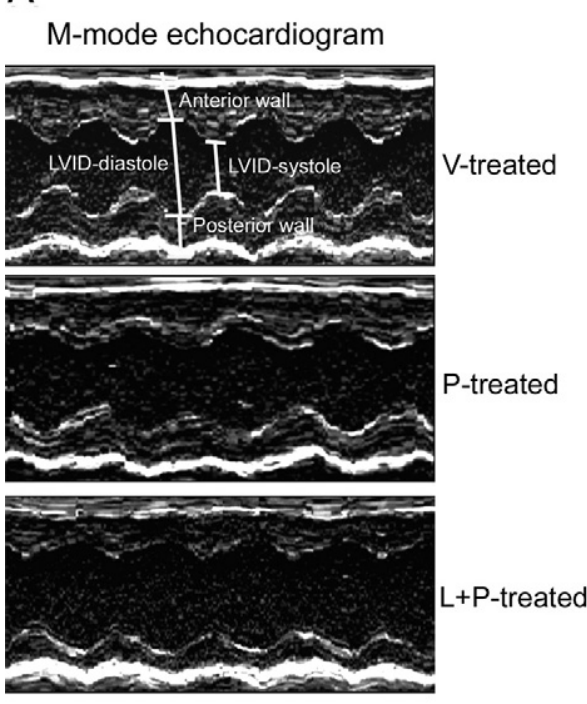

B
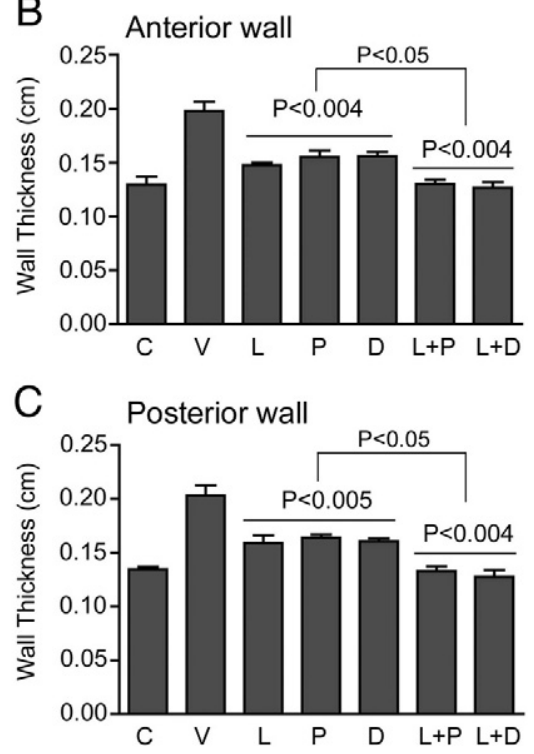

Figure 2. Echocardiographic analysis of left ventricular wall thickness. Every SHR in the study was analyzed by echocardiography at the end of the treatment. A: Representative M-mode echocardiographs from V-, P- and L+P-treated SHRs. The position of anterior and posterior walls is marked. Similar images were seen in D- and L + D-treated rats. $\mathbf{B}$ and $\mathbf{C}$ : Thickness of anterior wall $(\mathbf{B})$ and posterior wall $(\mathbf{C})$ of the left ventricle at the end of the treatment. The wall thickness was calculated based on the echocardiographic data. The $P$ values were for comparison with $\mathrm{V}$, and between $\mathrm{L}+\mathrm{P}$ or $\mathrm{L}+\mathrm{D}$ and $\mathrm{L}, \mathrm{P}$ or $\mathrm{D}$. C, nonhypertensive WKY rats.
SHRs developed hypertension, with systolic blood pressure reaching $>200 \mathrm{mmHg}$ at the end of the study (3 months of age). $L$ treatment reduced blood pressure by $31 \%$, whereas the two vitamin D analogs had much weaker effects (decreased by 9 to $14 \%$ ); the combination groups demonstrated little additive effects on blood pressure (Figure 1).

At the end of the study period we examined cardiac parameters using M-mode echocardiography (Figure 2A). As expected, V-treated SHRs developed LVH, with a marked increase in the thickness of the anterior and posterior left ventricular walls compared with those of the $C$ rats (Figure 2, $B$ and $C$ ). Monotreatment with $L, P$, or $D$ significantly reduced the wall thickness by similar degree (64 to $80 \%$, relative to the difference between $\mathrm{V}$-treated SHRs and WKY controls; Figure 2, B and C), despite the two vitamin $D$ analogs demonstrating minimal impact on blood pressure compared with losartan. Importantly, L+P or $L+D$ treatment completely prevented the increase of both anterior and posterior left ventricular wall thickness in SHR animals (Figure 2, B and C), suggesting a possible synergistic effect $(P<0.05$ compared with the mono-treatments).

The attenuation of cardiac hypertrophy by these treatments was confirmed by cardiac mass and histological data. Figure 3A shows that the heart weight to tibia length ratio was significantly reduced in all treatment groups, but $L$, $L+P$, and $L+D$ demonstrated more attenuation than $P$ and $D$ alone. Cross-sectional morphology of the left ventricle from these rats confirmed that the double treatment $(L+P$ and $L+D)$ reduced left ventricular wall thickness more than the monotherapy (Figure 3B). Close examination of the left ventricular cardiomyocytes whose plasma membranes were stained with FITC-labeled wheat germ agglutinin indicated that the monotherapy $(L, P$, and $D)$ reduced the diameter of cardiomyocytes by 20 to $27 \%$, whereas the combination treatment $(L+P$ and $L+D$ ) reduced diameter by $\sim 37 \%$ (Figure 3, $C$ and D), relative to $\mathrm{V}$-treated rats.
We then determined the levels of atrial natriuretic peptide (ANP) and brain natriuretic peptide (BNP), two known biomarkers of cardiac stress and hypertrophy, ${ }^{25}$ in the SHRs under these treatments. Northern blot anal-

A

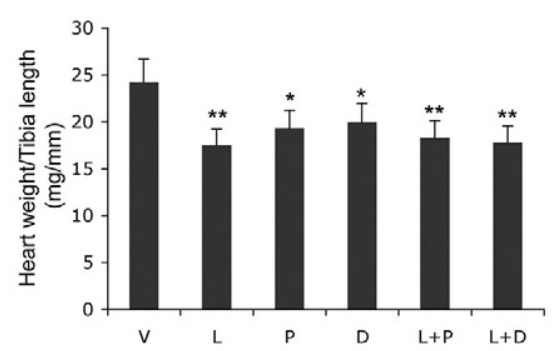

B

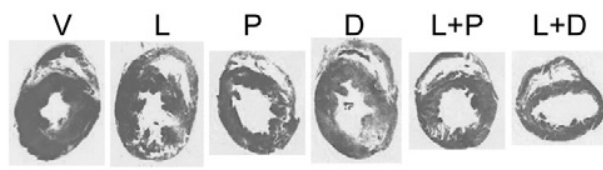

C

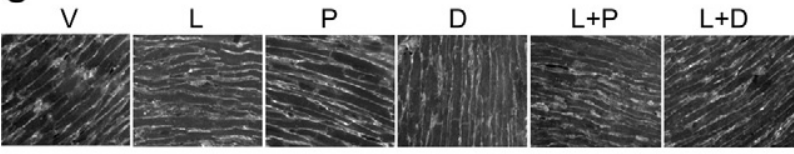

$\mathrm{D}$

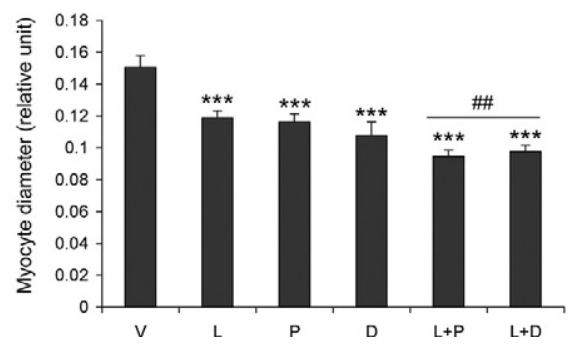

Figure 3. Heart morphology and histology. A: Heart weight to tibia length ratio in each treatment group of SHRs; B: H\&E staining of cross-sections of the left ventricles from each group of SHRs; $\mathbf{C}$ : left ventricular cardiomyocytes stained with FITC-labeled wheat germ agglutinin; D: diameter of left ventricular cardiomyocytes. ${ }^{*} P<0.05,{ }^{* *} P<0.01,{ }^{* * * *} P<0.001$ vs $\mathrm{V} ;{ }^{\# \#} P<0.01$ vs L, P or D. 


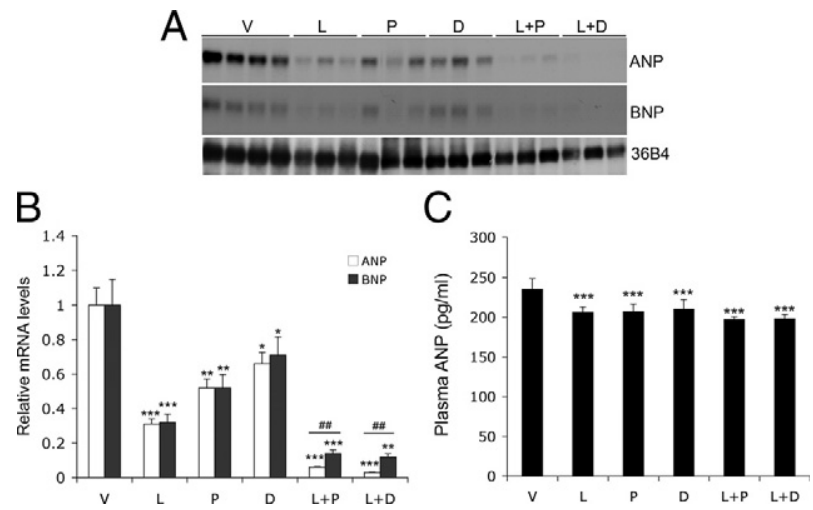

Figure 4. Effect of the treatments on ANP and BNP levels. A: Northern blot analyses. Total RNAs were extracted from the left ventricle, and the blots were hybridized with ${ }^{32}$ P-labeled ANP or BNP cDNA probe. B: ANP and BNP mRNA levels quantified using a PhosphoImaging system; C: plasma ANP levels determined by ELISA. ${ }^{*} P<0.05$, ${ }^{* * *} P<0.01,{ }^{* * * *} P<0.001 \mathrm{vs} \mathrm{V}$; ${ }^{\# \#} P<$ 0.01 vs $\mathrm{L}, \mathrm{P}$ or $\mathrm{D}$.

yses showed that the expression of both ANP and BNP mRNA transcripts in the left ventricle were markedly decreased in L-, P- or D-treated SHRs, but the reduction was even more dramatic in SHRs treated with $L+P$ or $L+D$, with a $>80 \%$ reduction (Figure $4, A$ and $B$ ). Similar findings were seen in plasma ANP levels in these SHRs, although the magnitude of reduction was smaller (Figure 4C).

To explore the molecular mechanism underlying the reduction in cardiac hypertrophy, we subjected the left ventricular RNAs to DNA and miRNA microarray analyses. To ensure reliability of the data, we used three separate RNA samples from each treatment group in these assays. Figure 5 summarizes the data obtained from the DNA microarray examination. Globally, compared with V-treated SHRs, 9 and 32 genes were down-regulated, and 1 and 0 gene up-regulated, in D- and P-treated rats, respectively; 73 genes were down-regulated and 29 genes were up-regulated in L-treatment (Figure 5A). Interestingly, in L+D and $L+P$ treated rats, there was a very dramatic increase in the number of up-regulated genes (126 and 105), while the number of down-regulated genes remained approximately the same as in the L-treated rats (105 and 57) (Figure 5A).

cDNA microarray analyses identified six genes downregulated in all treatment groups. These were natriuretic peptide precursor type A (ANP precursor), ankyrin repeat domain 23 (Ankrd 23), RGD1306959, transferrin receptor (Tfrc), ankyrin repeat domain 1 (Ankrd 1), and enabled homolog (Enah) (Table 1). Cluster analysis demonstrated that these six genes were down-regulated by all treatments in the order of $P, D, L, L+P$ and $L+D$, with the combination treatments demonstrating the most dramatic suppression (Figure 5B). This order of increasing inhibitory effect was also seen in the box plot analysis (Figure $5 \mathrm{C}$ ), and confirmed by the PCA analysis, where the first principal component was negatively correlated with the inhibitory effect (Figure 5D). These data provide a molecular basis to support a possible synergistic effect observed in the combination treatments.

miRNA array analyses revealed one miRNA species, miR-208b, which was significantly down-regulated by all
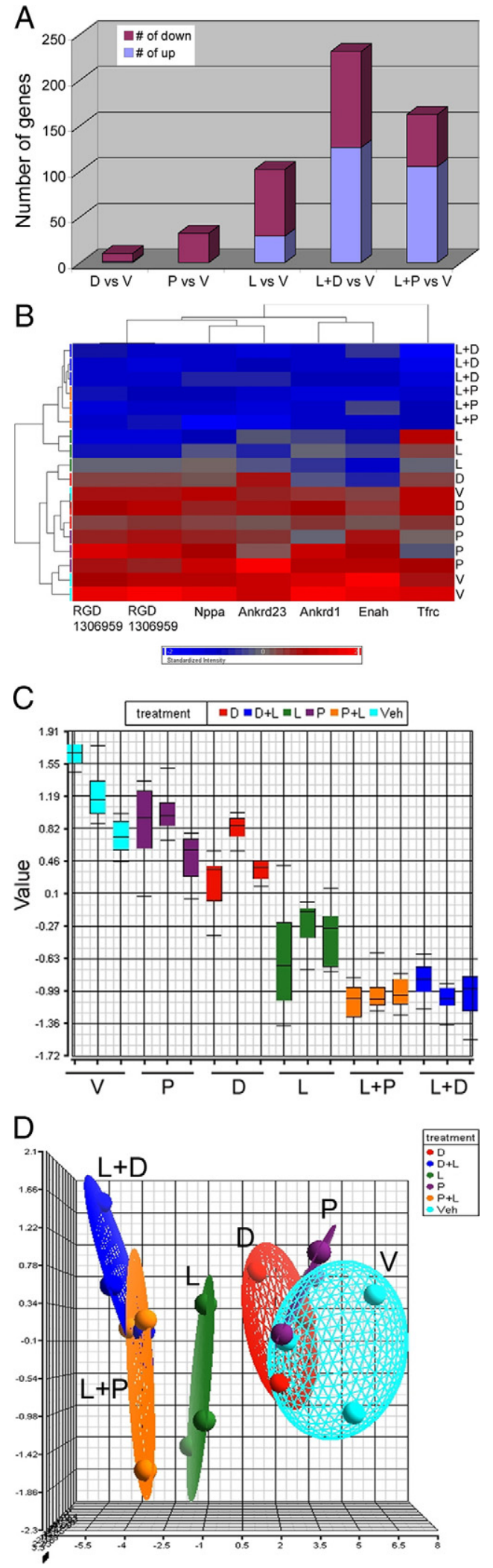

Figure 5. Microarray analysis of gene expression profiles in the left ventricle. A Number of genes down-regulated and up-regulated in each treatment group as indicated. B: Cluster analysis of the seven commonly regulated genes identified in all treatment groups as indicted. Red color: relatively high expression; Blue color: relatively low expression. C: Box plot showing the average value of the seven genes in each samples; D: Principal Component Analysis mapping showing the positional difference of each treatments in three-dimensional space. 
Table 1. Commonly Regulated Genes in All Treatment Groups

\begin{tabular}{|c|c|c|c|c|c|c|c|}
\hline Probeset ID & Gene title & Gene symbol & $\begin{array}{c}P \text { value } \\
\text { (treatment) }\end{array}$ & $\begin{array}{l}\text { Fold change } \\
(L+D \text { versus } V)\end{array}$ & $\begin{array}{c}P \text { value } \\
(L+D \text { versus } V)\end{array}$ & $\begin{array}{l}\text { Fold change } \\
(L+P \text { versus } V)\end{array}$ & $\begin{array}{c}P \text { value } \\
(L+P \text { versus } V)\end{array}$ \\
\hline 1367564_at & $\begin{array}{l}\text { Natriuretic peptide } \\
\text { precursor type A }\end{array}$ & Nppa (ANP) & $1.25 \mathrm{E}-05$ & -2.56158 & 1.83E-05 & -3.13124 & 2.63E-06 \\
\hline 1371927_at & $\begin{array}{c}\text { Ankyrin repeat } \\
\text { domain } 23\end{array}$ & Ankrd23 & 0.00010038 & -2.38864 & 0.000116778 & -2.73836 & 3.05E-05 \\
\hline 1383175_a_at & $\begin{array}{l}\text { Similar to C11orf17 } \\
\text { protein }\end{array}$ & RGD1306959 & 1.97E-05 & -2.38341 & $1.25 \mathrm{E}-05$ & -2.25891 & 2.32E-05 \\
\hline 1385458_a_at & $\begin{array}{l}\text { Similar to C11orf17 } \\
\text { protein }\end{array}$ & RGD1306959 & 4.81E-05 & -2.13811 & 6.39E-05 & -2.21042 & 4.30E-05 \\
\hline $\begin{array}{l}\text { 1388750_at } \\
\text { 1394747_at }\end{array}$ & $\begin{array}{l}\text { Transferrin receptor } \\
\text { Ankyrin repeat } \\
\text { domain } 1 \\
\text { (cardiac muscle) }\end{array}$ & $\begin{array}{l}\text { Tfro } \\
\text { Ankrd1 }\end{array}$ & $\begin{array}{c}1.81 \mathrm{E}-05 \\
0.00029515\end{array}$ & $\begin{array}{l}-3.04488 \\
-2.21\end{array}$ & $\begin{array}{c}2.42 \mathrm{E}-06 \\
0.00011074\end{array}$ & $\begin{array}{l}-2.37502 \\
-2.35856\end{array}$ & $\begin{array}{l}3.00 \mathrm{E}-05 \\
5.40 \mathrm{E}-05\end{array}$ \\
\hline 1396450_at & $\begin{array}{l}\text { Enabled homolog } \\
\text { (Drosophila) }\end{array}$ & Enah & 0.00039742 & -3.06028 & 0.00016458 & -3.11928 & 0.00014189 \\
\hline
\end{tabular}

Fold changes for these genes are presented only for the combination treatment groups.

treatments, except for $\mathrm{P}$ treatment (Table 2). Real time PCR quantification with a miR-208b-specific Taqman probe confirmed that miR-208b levels were significantly decreased by $\sim 30 \%$ in all treatment groups, including Ptreated SHRs, compared with V-treated animals (Figure 6). Previous work has linked miR-208 with cardiac hypertrophy. ${ }^{26}$

We designed this study based on the hypothesis that the combination treatment would more effectively inhibit the RAS by blocking the compensatory induction of renin. As expected, renin expression was dramatically increased at both mRNA (Figure 7A) and protein (Figure 7B) levels in the kidney by $L$ treatment, and the induction was localized mainly to juxtaglomerular cells, as evidenced by immunostaining (Figure $7 \mathrm{C}$ ). P- or D monotherapy reduced the baseline renin expression, and $L+P$ or $L+D$ effectively blocked the compensatory induction of renin seen in L-treated SHRs (Figure 7, A-C). Interestingly, RT-PCR showed that $L$ treatment also markedly induced renin expression in the left ventricle (Figure 7D). Similarly, the vitamin $D$ analogs inhibited the baseline renin expression, and the $\mathrm{L}+\mathrm{P}$ or $\mathrm{L}+\mathrm{D}$ combination blocked the compensatory renin induction in the heart (Figure 7D). Immuostaining of the left ventricular sections revealed renin expression mostly in the blood vessel walls, co-localized with CD31-positive endothelial cells (Figure $7 \mathrm{E})$. The renin expression is induced by losartan, which was markedly suppressed by the combination treatment (Figure $7 \mathrm{E})$. These data suggest that suppression of renin, and thus the RAS, in the kidney and heart may at least in part underlie the anti-hypertrophic action of vitamin D analogs. Blockade of the compensatory renin induction in combination treatment thus increases the efficacy of RAS inhibition.

Table 2. Changes of miR-208b Expression in the Left Ventricles from Different Treatment Groups

\begin{tabular}{lcc}
\hline Comparison & Fold change & $P$ value \\
\hline$L$ versus $V$ & -2.47 & 0.009 \\
$P$ versus $V$ & $n / a$ & $n / a$ \\
$D$ versus $V$ & -1.73 & 0.028 \\
$L+P$ versus $V$ & -1.77 & 0.068 \\
$L+D$ versus $V$ & -2.01 & 0.026 \\
\hline
\end{tabular}

The data were obtained from miRNA arrays.
Finally we assessed whether vitamin D analog therapy also suppresses renin in humans. We examined plasma renin activity in a small group of chronic dialysis patients previously naive to any form of vitamin $D$ therapy. Baseline and follow-up characteristics are shown in Table 3. The primary difference between these two patient groups was baseline levels of parathyroid hormone (Table 3), which was expected given that hyperparathyroidism is the primary indication for the use of vitamin $\mathrm{D}$ analogs. ${ }^{27}$ In this pilot study, plasma renin activity was significantly reduced following therapy with either $\mathrm{P}$ or $\mathrm{D}$ compared with subjects not treated with either (Figure 8), suggesting the renin-inhibiting activity of vitamin $D$ analogs extends to humans. Although the sample size was small, these results remained significant after adjusting for baseline parathyroid hormone levels $(P<0.01)$, but after adjustment for ACE/ARB use it was of borderline of significance $(P=0.064)$. We also measured blood aldosterone levels at these two time points, and found that in treated subjects the levels fell from 12.2 to $7.3 \mathrm{ng} / \mathrm{dl}$, whereas the levels in untreated subjects the levels fell from 8.4 to $7.6 \mathrm{ng} / \mathrm{dl}(P=0.38)$. Changes in potassium levels are provided in Table 3.

\section{Discussion}

In this study we demonstrated that two vitamin $\mathrm{D}$ analogs commonly used in the United States, paricalcitol

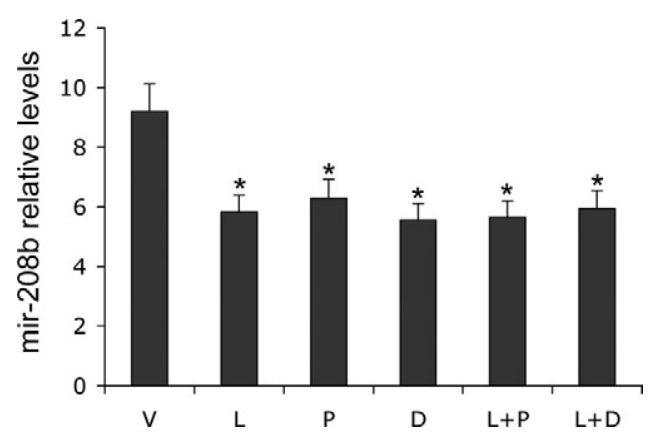

Figure 6. Effect of the treatments on mir-208b levels in the left ventricle TaqMan real-time PCR analyses confirm the down-regulation of mir-208b by all treatments as indicated. ${ }^{*} P<0.05$ vs $\mathrm{V} ; n=4$. 

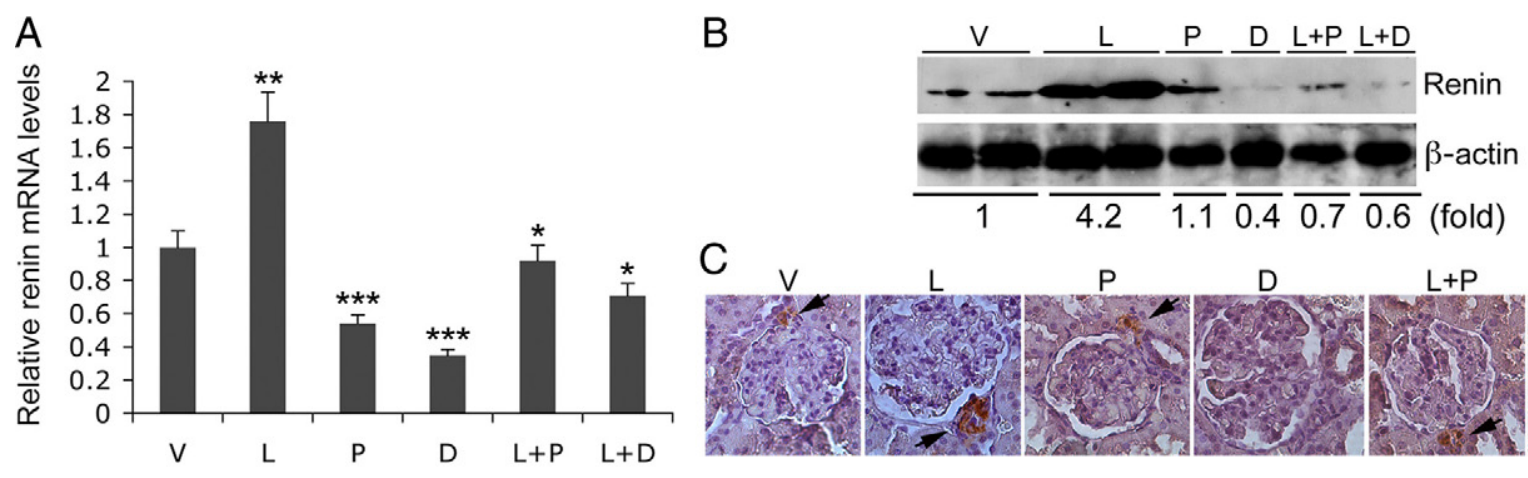

D
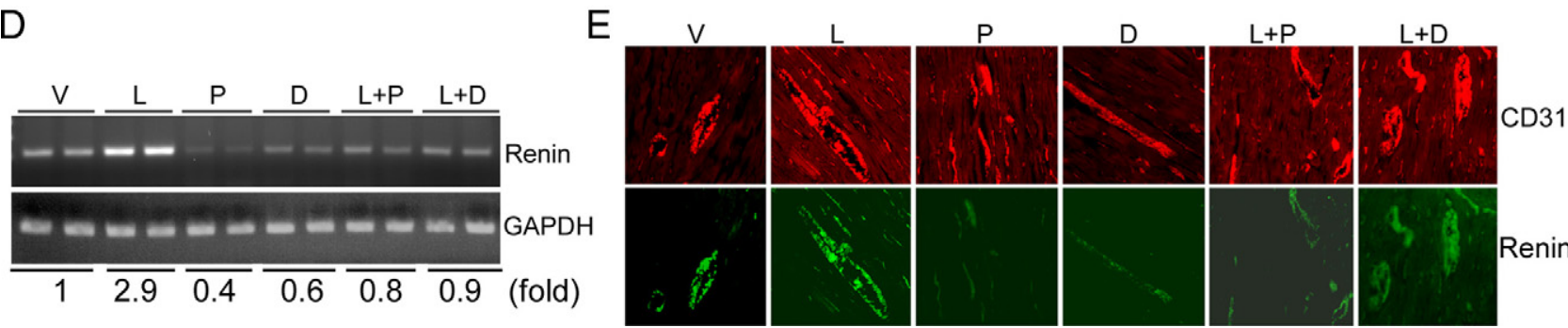

Figure 7. Effect of the drug treatments on renin expression in the kidney and heart. A: Real-time RT-PCR analyses of renin mRNA transcript in the kidney of treatment groups as indicated; ${ }^{*} P<0.05 ;{ }^{* *} P<0.01 \mathrm{vs} \mathrm{V;}{ }^{* * *} P<0.01 \mathrm{vs} \mathrm{L}$. B: Western blot analysis of renin protein levels, with relative fold changes shown at the bottom of the blot; C: immunostaining of kidney sections using anti-renin antibodies. Arrows indicate renin-expressing juxtaglomerular cells. D: RT-PCR determination of renin mRNA levels in the left ventricle of each treatment group as indicated, with relative fold changes shown at the bottom of the gel; $\mathbf{E}$ : immunostaining of left ventricular sections with anti-CD31 (upper panels, red) or anti-renin (lower panels, green) antibodies. Note that renin staining was mainly seen in the blood vessel walls.

and doxercalciferol, have strong anti-hypertrophic activity when given either as mono-therapy or in combination with the AT1 receptor blocker losartan. The mechanism underlying this activity, at least in part, appears to be the inhibition of renin expression in the kidney and the heart. Combination treatment with AT1 receptor blockade and vitamin $D$ analogs showed re- markable therapeutic enhancement against the development of $\mathrm{LVH}$, as a result of blockade of the compensatory induction of renin expression leading to improved RAS inhibition. At the molecular level, the therapeutic effect of these treatments was reflected by changes in hypertrophy gene markers as well as in global gene and miRNA profiles in the left ventricle of

Table 3. Characteristics at Baseline and Follow-Up of Vitamin D-Treated and Untreated End Stage Renal Failure Patients

\begin{tabular}{|c|c|c|c|}
\hline Baseline characteristic & Treated $N=17$ & Not treated $N=11$ & $P$ value \\
\hline $\begin{array}{l}\text { Age (yrs) } \\
\text { Sex - male } \\
\text { Race - Caucasian } \\
\text { Cause of ESRD: diabetes and/or hypertension } \\
\text { History of congestive heart failure } \\
\text { Taking ACE/ARB } \\
\text { Minutes of dialysis (per session) } \\
\text { Systolic blood pressure }(\mathrm{mm} \mathrm{Hg}) \\
\text { Diastolic blood pressure }(\mathrm{mm} \mathrm{Hg}) \\
\text { Potassium }(\mathrm{mg} / \mathrm{dl}) \\
\text { Albumin }(\mathrm{mg} / \mathrm{dl}) \\
\text { Calcium }(\mathrm{mg} / \mathrm{dl}) \\
\text { Phosphate }(\mathrm{mg} / \mathrm{dl}) \\
\text { Parathyroid hormone }(\mathrm{pg} / \mathrm{ml})\end{array}$ & $\begin{array}{c}65 \pm 14 \\
61 \% \\
100 \% \\
77 \% \\
0 \% \\
29 \% \\
212 \pm 26 \\
137 \pm 20 \\
70 \pm 10 \\
4.4 \pm 0.6 \\
3.5 \pm 0.5 \\
8.2 \pm 0.5 \\
5.9 \pm 2.2 \\
275 \pm 189\end{array}$ & $\begin{array}{l}62 \pm 14 \\
57 \% \\
100 \% \\
78 \% \\
18 \% \\
18 \% \\
208 \pm 29 \\
140 \pm 21 \\
73 \pm 14 \\
4.5 \pm 1.5 \\
3.4 \pm 0.4 \\
8.2 \pm 0.8 \\
6.1 \pm 1.8 \\
93 \pm 47\end{array}$ & $\begin{array}{l}\text { NS } \\
\text { NS } \\
\text { NS } \\
\text { NS } \\
\text { NS } \\
\text { NS } \\
\text { NS } \\
\text { NS } \\
\text { NS } \\
\text { NS } \\
\text { NS } \\
\text { NS } \\
\text { NS } \\
<0.05\end{array}$ \\
\hline $\begin{array}{l}\text { Follow-up characteristic ( } 90 \text { days) } \\
\text { Taking ACE/ARB } \\
\text { Minutes of dialysis (per session) } \\
\text { Systolic blood pressure }(\mathrm{mm} \mathrm{Hg}) \\
\text { Diastolic blood pressure }(\mathrm{mm} \mathrm{Hg}) \\
\text { Potassium }(\mathrm{mg} / \mathrm{dl}) \\
\text { Albumin }(\mathrm{mg} / \mathrm{dl}) \\
\text { Calcium }(\mathrm{mg} / \mathrm{dl}) \\
\text { Phosphate }(\mathrm{mg} / \mathrm{dl}) \\
\text { Parathyroid hormone (pg/ml) }\end{array}$ & $\begin{aligned} 0 \% \\
212 \pm 27 \\
146 \pm 25 \\
74 \pm 12 \\
4.6 \pm 0.6 \\
3.6 \pm 0.5 \\
8.9 \pm 0.7 \\
4.9 \pm 1.5 \\
212 \pm 207\end{aligned}$ & $\begin{array}{c}9 \% \\
211 \pm 26 \\
148 \pm 33 \\
76 \pm 18 \\
4.3 \pm 0.4 \\
3.5 \pm 0.5 \\
9.0 \pm 0.5 \\
5.1 \pm 1.6 \\
50 \pm 28\end{array}$ & $\begin{array}{l}\text { NS } \\
\text { NS } \\
\text { NS } \\
\text { NS } \\
\text { NS } \\
\text { NS } \\
\text { NS } \\
\text { NS } \\
<0.05\end{array}$ \\
\hline
\end{tabular}




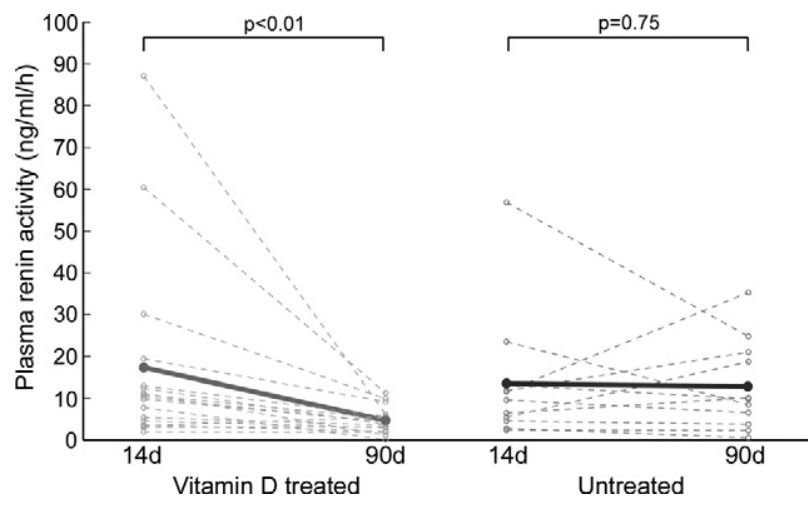

Figure 8. Suppression of plasma renin activity by vitamin D therapy in hemodialysis patients. Plasma renin activity declined significantly between 14 and 90 days of dialysis in patients who received $\geq 30$ days of active vitamin $D$ therapy ( $n=17, P<0.01$ ) but not in subjects who received no vitamin $\mathrm{D}$ analogs during this period ( $n=11, P=0.75$ ). The difference in effect between treated and untreated patients was statistically significant $(P=0.025)$

SHRs. The renin-inhibiting activity of the vitamin D analog therapy was confirmed in a small number of chronic hemodialysis patients; however, these clinical data are still preliminary and more studies are needed to confirm that vitamin $\mathrm{D}$ analogs reduce plasma renin activity in humans.

The experimental evidence linking these treatments to a reduction in $\mathrm{LVH}$ is compelling. Morphological evidence includes the remarkable decrease in the heart weight, left ventricular wall thickness, and cardiomyocyte size relative to the vehicle-treated controls. At the molecular level, ANP and BNP were markedly suppressed. The data obtained from the cDNA and miRNA microarrays provide further support for the anti-hypertrophic effect of these treatments. DNA microarrays identified six genes in the left ventricle that were down-regulated in all treatment groups. Of these six genes, at least four have been directly linked with cardiac hypertrophy. Natriuretic peptide precursor type A (Nppa), the precursor of ANP, is a well-known marker of cardiac hypertrophy, and its induction is regarded as a cardioprotective response because of associated natriuretic, antihypertrophic, and antihypertensive activities. ${ }^{28}$ Ankyrin repeat domain 1 (Ankrd1), also named CARP, is highly induced during the development of cardiac hypertrophy and is considered as a new genetic marker of cardiac hypertrophy. ${ }^{29}$ It is plausible that ankyrin repeat domain 23 (Ankrd23) is also linked to cardiac hypertrophy. Transferrin receptor (Tfrc) functions to import transferrin Fe into cells, and enhanced transferring receptor expression was found to increase mitochondrial Fe loading in myocardium, leading to myocardial hypertrophy in a Friedreich's ataxia model. ${ }^{30}$ The relationship of RGD1306959 and Enah to cardiac hypertrophy remains to be determined. It is intriguing that miRNA arrays identified miR-208b as the only miRNA species significantly down-regulated in the left ventricle in almost all treatment groups; this result was confirmed by real time PCR analyses. The heart-specific miR-208 is encoded in an intron of the $\alpha$-myosin heavy chain gene and its role in the development of cardiac hypertrophy has been well established by elegant genetic studies in mice. ${ }^{26}$ van Rooij et $\mathrm{al}^{26}$ demonstrated that miR-208 is required for the development of cardiac hypertrophy, and genetic deletion of miR-208 reduces cardiac hypertrophy in response to pressure overload in mice.

Our finding that similar results were obtained from two separate vitamin D analogs provides robust evidence for the link between vitamin $D$, renin suppression, and LVH attenuation. Although paricalcitol and doxercalciferol were less effective antihypertensive compared with losartan, they appeared to be as effective as losartan in attenuation of LVH. This finding was particularly evident in the echocardiographic analysis, suggesting that the effect of vitamin D analogs on LVH is likely independent of blood pressure. This is consistent with a prior observation that paricalcitol suppressed LVH in Dahl salt-sensitive rats without modifying blood pressure ${ }^{20}$ and with studies demonstrating that renin can be suppressed without marked reduction in blood pressure. ${ }^{31}$ These agents target different steps of the RAS: while vitamin D analogs inhibit renin production, losartan reduces AT1 receptor activity. Whereas losartan induced renin expression in both the kidney and the heart, the vitamin D analogs suppressed renin expression in these organs. Previous studies have demonstrated that $1,25(\mathrm{OH})_{2} \mathrm{D}_{3}$ suppresses renin gene transcription by disrupting the CAMP signaling pathway, a major regulatory pathway involved in renin biosynthesis. ${ }^{10}$ The suppression of renin in the heart is particularly intriguing. Previous studies showed that the expression of some components of the RAS, including renin, are increased in the heart of SHRs, ${ }^{32-35}$ suggesting that the local RAS activity may play a role in the development of cardiac hypertrophy. We previously observed that activation of the cardiac RAS was associated with cardiac hypertrophy in vitamin $D$ receptor-null mice. ${ }^{18}$ Therefore, while blockade of the systemic RAS may be responsible for the antihypertrophic effect of losartan, inhibition of the local cardiac RAS by vitamin D analogs may suppress the development of LVH in SHRs. The possibility, however, of vitamin D analogs directly inhibiting cardiac hypertrophy via vitamin D receptor ${ }^{36}$ was not excluded in this study. The origin of cardiac renin is controversial. Cardiac renin can be derived from cardiac mast cells, ${ }^{37}$ and mast cell renin has been shown to promote arrhythmias. ${ }^{38}$ Here our immunostaining data showed that renin is highly induced by losartan in the blood vessel walls in the left ventricle, and this finding is consistent with our previous report that renin expression was detected in the vasculatures in mouse brain. ${ }^{39}$ The exact role of endothelial renin deserves further investigations.

It is notable that vitamin $D$ analogs inhibit renin expression, unlike renin enzymatic inhibitors such as aliskiren, ${ }^{40}$ which induces compensatory renin expression. ${ }^{41}$ It is conceivable that, by decreasing renin production, vitamin D analogs suppress not only Ang II-dependent activity, but also (pro)renin receptor-dependent activity, ${ }^{42}$ both of which can cause cardiac injury. ${ }^{43}$ In fact, Ang II can directly induce cardiomyocyte hypertrophy independent of its blood pressure-elevating activity, ${ }^{25,44-46}$ and this effect may be targeted by vitamin $D$ analogs in the SHR model via suppression of renin. 
Our data provide evidence that the combination of vitamin $\mathrm{D}$ analogs with losartan generates a degree of therapeutic synergism in the attenuation of LVH. The superiority of the combination therapy over the monotherapy is supported by morphological, histological and molecular data, including the reduction of left ventricular wall thickness and cardiomyocyte size and the magnitude of ANP and BNP inhibition (see Figures 2-4). Gene cluster analysis similarly showed that the six genes identified by cDNA microarrays underwent greater down-regulation in the combination treatment groups than in the mono-therapy groups. Interestingly, the left ventricular gene expression profiles in the combination-treated groups do not appear to be a simple additive combination of those from the mono-therapy groups. Thus, these molecular signatures support a synergistic nature of the combination strategy.

We previously demonstrated that the primary mechanism for the enhanced therapeutic efficacy of vitamin $D$ analog and AT1 blocker combination in the treatment of diabetic nephropathy is the blockade of the compensatory induction of renin in the kidney, which complements the effects of local RAS inhibition. ${ }^{16,17}$ Here we showed that the compensatory renin increase associated with losartan occurs in both the kidney and heart, which may lead to accumulation of Ang II in both the systemic circulation and the local cardiac environment. The combination therapy blocked the induction of renin and thus Ang II in both organs, further suggesting that the analogs target the local cardiac RAS.

The pilot human data represent initial observations in subjects undergoing routine chronic hemodialysis and are not part of a randomized trial. Accordingly, it was expected that subjects receiving activated vitamin $D$ would have higher levels of blood parathyroid hormone. ${ }^{47}$ It is possible therefore that this may have confounded the relationship we observed. It was interesting to note that therapy in dialysis did not lead to significant changes in blood pressure. Many other factors contribute to blood pressure changes in these patients (volume status, volume removal, change in medications), and plasma renin activity in treated subjects reached a nadir of only $\sim 5 \mathrm{ng} / \mathrm{ml} / \mathrm{h}$ (Figure 8 ), which is still at least 5 - to 10-fold higher than levels achieved with doses of renin inhibitors that correspond to blood pressure reduction. ${ }^{48}$ We did not observe significant changes in blood aldosterone levels, although levels tended to decrease in treated subjects. A portion of our subjects were taking ACE/ARB medications, which is common in this population, and a large sample size will be needed to determine whether these observations are independent of ACE/ARB use.

Paricalcitol is an activated vitamin D analog and doxercalciferol a prodrug that is activated in vivo by hepatic 25-hydroxylase. Despite this difference, their anti-hypertrophic activity appears to be similar in terms of potency and efficacy at the doses used in our experimental model. Therapy with RAS inhibitors in renal failure is often limited by hyperkalemia, possibly explaining why few patients in our population (Table 3 ) were receiving this therapy. Vitamin D analogs, which lack these effects on potassium handling, may thus be useful adjuncts in pa- tients with renal impairment. Given the superior efficacy shown in this study, the combination therapy also warrants further clinical investigation. An ongoing multinational randomized clinical trial in subjects with chronic kidney disease (www.clinicaltrials.gov NCT 00497146) is testing whether paricalcitol prevents the progression or induces regression of $\mathrm{LVH}$, and whether changes in plasma renin activity - as suggested by the current study - will correlate with cardiac structural changes.

There are limitations and unaddressed questions in this study. The vitamin $D$ analogs were given via intraperitoneal injection, and it is unclear whether oral delivery is also effective. It also remains unclear whether the treatment can regress or permanently inhibit cardiac hypertrophy in this model. These questions need to be addressed in future investigations.

\section{References}

1. Martins D, Wolf M, Pan D, Zadshir A, Tareen N, Thadhani R, Felsenfeld A, Levine B, Mehrotra R, Norris K: Prevalence of cardiovascular risk factors and the serum levels of 25-hydroxyvitamin $D$ in the United States: data from the Third National Health and Nutrition Examination Survey. Arch Intern Med 2007, 167:1159-1165

2. Melamed ML, Michos ED, Post W, Astor B: 25-hydroxyvitamin D levels and the risk of mortality in the general population. Arch Intern Med 2008, 168:1629-1637

3. Dobnig H, Pilz S, Scharnagl H, Renner W, Seelhorst U, Wellnitz B, Kinkeldei J, Boehm BO, Weihrauch G, Maerz W: Independent association of low serum 25-hydroxyvitamin $d$ and 1,25-dihydroxyvitamin $\mathrm{D}$ levels with all-cause and cardiovascular mortality. Arch Intern Med 2008, 168:1340-1349

4. Zittermann A, Schleithoff SS, Tenderich G, Berthold HK, Korfer R, Stehle P: Low vitamin D status: a contributing factor in the pathogenesis of congestive heart failure? J Am Coll Cardiol 2003, 41:105-112

5. Wang TJ, Pencina MJ, Booth SL, Jacques PF, Ingelsson E, Lanier K, Benjamin EJ, D'Agostino RB, Wolf M, Vasan RS: Vitamin D deficiency and risk of cardiovascular disease. Circulation 2008, 117:503-511

6. Giovannucci E, Liu Y, Hollis BW, Rimm EB: 25-hydroxyvitamin D and risk of myocardial infarction in men: a prospective study. Arch Intern Med 2008, 168:1174-1180

7. Shoji T, Shinohara K, Kimoto E, Emoto M, Tahara H, Koyama H, Inaba M, Fukumoto S, Ishimura E, Miki T, Tabata T, Nishizawa Y: Lower risk for cardiovascular mortality in oral $1 \alpha$-hydroxy vitamin $D_{3}$ users in a haemodialysis population. Nephrol Dial Transplant 2004, 19:179-184

8. Teng M, Wolf M, Ofsthun MN, Lazarus JM, Hernan MA, Camargo CA, Jr., Thadhani R: Activated injectable vitamin D and hemodialysis survival: a historical cohort study. J Am Soc Nephrol 2005, 16:1115-1125

9. Li YC, Kong J, Wei M, Chen ZF, Liu SQ, Cao LP: 1,25-Dihydroxyvita$\min D_{3}$ is a negative endocrine regulator of the renin-angiotensin system. J Clin Invest 2002, 110:229-238

10. Yuan W, Pan W, Kong J, Zheng W, Szeto FL, Wong KE, Cohen R, Klopot A, Zhang Z, Li YC: 1,25-Dihydroxyvitamin $D_{3}$ suppresses renin gene transcription by blocking the activity of the cyclic AMP response element in the renin gene promoter. J Biol Chem 2007 , 282:29821-29830

11. Qiao G, Kong J, Uskokovic M, Li YC: Analogs of 1 $\alpha, 25$-dihydroxyvitamin $D_{3}$ as novel inhibitors of renin biosynthesis. J Steroid Biochem Mol Biol 2005, 96:59-66

12. Resnick LM, Muller FB, Laragh JH: Calcium-regulating hormones in essential hypertension: relation to plasma renin activity and sodium metabolism, Ann Intern Med 1986, 105:649-654

13. Burgess ED, Hawkins RG, Watanabe M: Interaction of 1,25-dihydroxyvitamin $D$ and plasma renin activity in high renin essential hypertension. Am J Hypertens 1990, 3:903-905

14. Muller DN, Luft FC: Direct renin inhibition with aliskiren in hypertension and target organ damage. Clin J Am Soc Nephrol 2006, $1: 221-228$ 
15. Li YC: Renoprotective effects of vitamin D analogs. Kidney Int 2009, doi: 10.1038/ki.2009.175

16. Zhang Z, Zhang Y, Ning G, Deb DK, Kong J, Li YC: Combination therapy with AT1 blocker and vitamin D analog markedly ameliorates diabetic nephropathy: blockade of compensatory renin increase. Proc Natl Acad Sci USA 2008, 105:15896-15901

17. Zhang Y, D.K. D, Kong J, Ning G, Wong Y, Li G, Chen Y, Zhang Z, Strugnell S, Sabbagh Y, Arbeeny C, Li YC: Long-term therapeutic effect of vitamin $D$ analog doxercalciferol on diabetic nephropathy: strong synergism with AT1 receptor antagonist. Am J Physio Renal Physiol 2009, 297:F791-F801

18. Xiang W, Kong J, Chen S, Cao LP, Qiao G, Zheng W, Liu W, Li X, Gardner DG, Li YC: Cardiac hypertrophy in vitamin D receptor knockout mice: role of the systemic and cardiac renin-angiotensin systems. Am J Physiol Endocrinol Metab 2005, 288:E125-E132

19. Zhou C, Lu F, Cao K, Xu D, Goltzman D, Miao D: Calcium-independent and $1,25(\mathrm{OH}) 2 \mathrm{D}_{3}$-dependent regulation of the renin-angiotensin system in 1 $\alpha$-hydroxylase knockout mice. Kidney Int 2008, 74:170-179

20. Bodyak N, Ayus JC, Achinger S, Shivalingappa V, Ke Q, Chen YS, Rigor DL, Stillman I, Tamez H, Kroeger PE, Wu-Wong RR, Karumanchi SA, Thadhani R, Kang PM: Activated vitamin D attenuates left ventricular abnormalities induced by dietary sodium in Dahl saltsensitive animals, Proc Natl Acad Sci USA 2007, 104:16810-16815

21. Li YC, Bolt MJG, Cao L-P, Sitrin MD: Effects of vitamin D receptor inactivation on the expression of calbindins and calcium metabolism. Am J Physiol Endocrinol Metab 2001, 281:E558-E564

22. Church GM, Gilbert W: Genomic sequencing, Proc Natl Acad Sci USA 1984, 81:1991-1995

23. Zhang Z, Sun L, Wang Y, Ning G, Minto AW, Kong J, Quigg RJ, Li YC: Renoprotective role of the vitamin $\mathrm{D}$ receptor in diabetic nephropathy. Kidney Int 2008, 73:163-171

24. Freundlich M, Quiroz Y, Zhang Z, Zhang Y, Bravo Y, Weisinger JR, Li YC, Rodriguez-Iturbe B: Suppression of renin-angiotensin gene expression in the kidney by paricalcitol. Kidney Int 2008, 74:1394-1402

25. Chien KR, Knowlton KU, Zhu H, Chien S: Regulation of cardiac gene expression during myocardial growth and hypertrophy: molecular studies of an adaptive physiologic response. FASEB J 1991, 5:3037-3046

26. van Rooij E, Sutherland LB, Qi X, Richardson JA, Hill J, Olson EN: Control of stress-dependent cardiac growth and gene expression by a microRNA. Science 2007, 316:575-579

27. Teng M, Wolf M, Lowrie E, Ofsthun N, Lazarus JM, Thadhani R: Survival of patients undergoing hemodialysis with paricalcitol or calcitriol therapy. N Engl J Med 2003, 349:446-456

28. Levin ER, Gardner DG, Samson WK: Natriuretic peptides. N Engl J Med 1998, 339:321-328

29. Aihara $Y$, Kurabayashi M, Saito $Y$, Ohyama $Y$, Tanaka T, Takeda S, Tomaru K, Sekiguchi K, Arai M, Nakamura T, Nagai R: Cardiac ankyrin repeat protein is a novel marker of cardiac hypertrophy: role of M-CAT element within the promoter. Hypertension 2000, 36:48-53

30. Whitnall M, Rahmanto YS, Sutak R, Xu X, Becker EM, Mikhael MR, Ponka P, Richardson DR: The MCK mouse heart model of Friedreich's ataxia: alterations in iron-regulated proteins and cardiac hypertrophy are limited by iron chelation. Proc Natl Acad Sci USA 2008, 105:9757-9762

31. Nussberger J, Wuerzner G, Jensen C, Brunner HR: Angiotensin II suppression in humans by the orally active renin inhibitor Aliskiren (SPP100): comparison with enalapril. Hypertension 2002, 39:E1-E8

32. Tamura K, Umemura S, Nyui N, Yamakawa T, Yamaguchi S, Ishigami
T, Tanaka S, Tanimoto K, Takagi N, Sekihara H, Murakami K, Ishii M: Tissue-specific regulation of angiotensinogen gene expression in spontaneously hypertensive rats. Hypertension 1996, 27:1216-1223

33. Naito $Y$, Tsujino $T$, Fujioka $Y$, Ohyanagi M, Iwasaki T: Augmented diurnal variations of the cardiac renin-angiotensin system in hypertensive rats. Hypertension 2002, 40:827-833

34. Jurkovicova D, Dobesova Z, Kunes J, Krizanova O: Different expression of renin-angiotensin system components in hearts of normotensive and hypertensive rats. Physiol Res 2001, 50:35-42

35. Sano H, Okamoto H, Kitabatake A, lizuka K, Murakami T, Kawaguch $\mathrm{H}$ : Increased mRNA expression of cardiac renin-angiotensin system and collagen synthesis in spontaneously hypertensive rats. Mol Cell Biochem 1998, 178:51-58

36. Wu J, Garami M, Cheng T, Gardner DG: 1,25(OH)2 vitamin $D_{3}$, and retinoic acid antagonize endothelin- stimulated hypertrophy of neonatal rat cardiac myocytes. J Clin Invest 1996, 97:1577-1588

37. Silver RB, Reid AC, Mackins CJ, Askwith T, Schaefer U, Herzlinger D, Levi R: Mast cells: a unique source of rennin. Proc Natl Acad Sci USA 2004, 101:13607-13612

38. Mackins CJ, Kano S, Seyedi N, Schafer U, Reid AC, Machida T, Silver RB, Levi R: Cardiac mast cell-derived renin promotes local angiotensin formation, norepinephrine release, and arrhythmias in ischemia/ reperfusion. J Clin Invest 2006, 116:1063-1070

39. Kong J, Zhang Z, Li D, Wong KE, Zhang Y, Szeto FL, Musch MW, Li YC: Loss of vitamin $D$ receptor produces polyuria by increasing thirst. J Am Soc Nephrol 2008, 19:2396-2405

40. Wood JM, Maibaum J, Rahuel J, Grutter MG, Cohen NC, Rasetti V, Ruger H, Goschke R, Stutz S, Fuhrer W, Schilling W, Rigollier P, Yamaguchi Y, Cumin F, Baum HP, Schnell CR, Herold P, Mah R, Jensen C, O'Brien E, Stanton A, Bedigian MP: Structure-based design of aliskiren, a novel orally effective renin inhibitor. Biochem Biophys Res Commun 2003, 308:698-705

41. Azizi M, Menard J, Bissery A, Guyenne TT, Bura-Riviere A, Vaidyanathan S, Camisasca RP: Pharmacologic demonstration of the synergistic effects of a combination of the renin inhibitor aliskiren and the AT1 receptor antagonist valsartan on the angiotensin II-renin feedback interruption. J Am Soc Nephrol 2004, 15:3126-3133

42. Nguyen G, Delarue F, Burckle C, Bouzhir L, Giller T, Sraer JD: Pivotal role of the renin/prorenin receptor in angiotensin II production and cellular responses to renin. J Clin Invest 2002, 109:1417-1427

43. Veniant M, Menard J, Bruneval P, Morley S, Gonzales MF, Mullins J: Vascular damage without hypertension in transgenic rats expressing prorenin exclusively in the liver. J Clin Invest 1996, 98:1966-1970

44. Baker KM, Booz GW, Dostal DE: Cardiac actions of angiotensin II: role of an intracardiac renin-angiotensin system. Annu Rev Physiol 1992, 54:227-241

45. Mazzolai L, Nussberger J, Aubert JF, Brunner DB, Gabbiani G, Brunner HR, Pedrazzini T: Blood pressure-independent cardiac hypertrophy induced by locally activated renin-angiotensin system. Hypertension 1998, 31:1324-1330

46. Dostal DE, Baker KM: Angiotensin II stimulation of left ventricular hypertrophy in adult rat heart: mediation by the AT1 receptor. Am J Hypertens 1992, 5:276-280

47. Thadhani R: Activated vitamin D sterols in kidney disease. Lancet 2008, 371:542-544

48. Stanton A, Jensen C, Nussberger J, O'Brien E: Blood pressure lowering in essential hypertension with an oral renin inhibitor, aliskiren. Hypertension 2003, 42:1137-1143 